\title{
Article \\ Effects of Task Demands on Postural Control in Children of Different Ages: A Cross-Sectional Study
}

\author{
Asiyeh Ghanbarzadeh ${ }^{1}$, Elaheh Azadian ${ }^{1}$, Mahdi Majlesi ${ }^{2}$, Amir Ali Jafarnezhadgero ${ }^{3}$ \\ and Mohammad Akrami ${ }^{4, *}$ (D) \\ 1 Department of Motor Behavior, Faculty of Humanities, Islamic Azad University, Hamedan Branch, \\ Hamedan 65141, Iran; ghanbarzadeh@iauh.ac.ir (A.G.); azadian@iauh.ac.ir (E.A.) \\ 2 Department of Sport Biomechanics, Faculty of Humanities, Islamic Azad University, Hamedan Branch, \\ Hamedan 65141, Iran; majlesi@iauh.ac.ir \\ 3 Department of Sport Managements and Biomechanics, Faculty of Educational Science and Psychology, \\ University of Mohaghegh Ardabili, Ardabil 56131, Iran; a.jafarnezhad@uma.ac.ir \\ 4 Department of Engineering, University of Exeter, Exeter EX4 4QF, UK \\ * Correspondence: M.AKRAMI@exeter.ac.uk
}

check for updates

Citation: Ghanbarzadeh, A.;

Azadian, E.; Majlesi, M.;

Jafarnezhadgero, A.A.; Akrami, M. Effects of Task Demands on Postural Control in Children of Different Ages: A Cross-Sectional Study. Appl. Sci. 2022, 12, 113. https://doi.org/ 10.3390/app12010113

\section{Academic Editor:}

Jorge López-Fernández

Received: 29 October 2021

Accepted: 17 December 2021

Published: 23 December 2021

Publisher's Note: MDPI stays neutral with regard to jurisdictional claims in published maps and institutional affiliations.

Copyright: (c) 2021 by the authors. Licensee MDPI, Basel, Switzerland. This article is an open access article distributed under the terms and conditions of the Creative Commons Attribution (CC BY) license (https:/ / creativecommons.org/licenses/by/ $4.0 /)$.

\begin{abstract}
This study evaluates the effect of dual tasks on balance during manipulation of visual information, the base of support, and cognitive tasks in 7-12-year-old children and adults. An equal number of girls (210) and boys (210) were selected from the schools by the cluster random sampling method (within the 7-12 age groups). Twenty young adults were also selected. Postural sway (PS) was measured in the anterior-posterior (AP) and mediolateral (ML) directions using a force plate in eight standing positions, including standing with closed eyes versus standing with open eyes and standing with feet together versus on a single limb, under the interference of cognitive dual tasks (DT) or a single task (ST). PS was found to decrease with advancing age. PS was also greater in men than women in both AP and ML directions $(p<0.05)$. PS was greater in the 7-12-year-old participants compared to adults under the manipulation of the base of support $(p<0.05)$. However, PS increased in all participants regardless of their age while manipulating both the base of support and visual information $(p<0.05)$. Children (within the 9-12 years age range) and adults could keep their balance while performing basic tasks; however, children had difficulty in maintaining their balance with higher task demands.
\end{abstract}

Keywords: age; gender; postural sway; visual manipulation; dual task

\section{Introduction}

Standing on both legs independently toward the end of the first year is one of the milestones of motor development [1]. Balance refers to the ability to maintain static and dynamic postural stability, which is crucial for daily activities and basic motor skills [2]. Balance control is an equilibrium between stabilizing and destabilizing forces by combining sensory information from visual, vestibular, and somatosensory systems and sending the information to the central nervous system to activate the appropriate motor responses to maintain balance in the center of gravity within the base of support [3]. Control of balance in the standing position depends on several factors, including interference or manipulation of the sensory systems [4,5] and the position of the legs [5]. Other factors are also involved in balance control in addition to sensory information. Researchers acknowledged that optimum balance control also depends on attentional requirements of postural control [6].

Postural control was evaluated in various experiments. Some assessed dynamic balance [7] and others evaluated static balance - the ability to maintain an upright posture [8,9]. In some studies, the relationship between cognitive and motor function has been investigated by a dual-task paradigm in which two tasks compete for attentional sources [6,10-12]. In the dual-task method, to perform two tasks simultaneously, it is necessary to divide the attention between the two tasks, which often includes a motor task with a cognitive 
task $[13,14]$. This has been described by several theories. Central bottleneck theory states that due to a narrow information-processing path, only one task is processed at a time. The processing of the second task does not start until the processing of the first task is completed. This narrow path will increase the response time for one or both tasks in the dual-task method [15]. The multiple-resource model, in contrast to the previous theory, states that interference between two tasks occurs when there is competition between simultaneous tasks in the processing stages, information processing codes, and sensory involvement. Finally, the theory of attentional resources states that a decrease in motor-cognitive performance is due to interference in the competition for obtaining attentional resources, and as a result, the attentional resources available for one or both tasks are reduced [16].

Some studies showed that motor tasks (especially difficult motor tasks) affect cognitive performance and disrupt cognitive tasks $[12,17]$. However, other studies showed that concurrent cognitive tasks increased PS and interfered with motor tasks $[4,18,19]$. Nevertheless, some showed that PS decreased while performing cognitive tasks concurrently [20-22]. A comparison between these studies is almost impossible due to the diversity of dual and motor tasks $[23,24]$, age and number of subjects $[23,25,26]$, the objective of the study $[27,28]$, and also the instruction and method of data collection $[23,27]$.

The development of balance performance throughout youth is an area of particular research interest as it may assist in the early identification of diseases and/or disorders, designing training regimes, or understanding deteriorating balance performance in older adults and seniors. The underlying developmental processes have been investigated in detail and it has been shown that physical factors (e.g., growth, weight gain) only marginally influence balance performance in youth [29]. In fact, improved sensory integration [30,31], the task-specific use of different postural control strategies [32], and progressive brain maturation [33] particularly account for improvements in balance performance in youth. However, there is still conflicting evidence whether these developments lead to differences in balance performance between school-aged children (6-12 years) and adolescents (13-18 years) in favor of the first or the latter. Some authors found adult-like balance performance in children at the end of the first decade of life (7-10 years old [34] and 11-13 years old [35]), indicating equal or even better balance performances of children compared to adolescents. Other studies [36], however, reported better balance performances of adolescents compared to children. Hence, the true extent of age-related differences in balance performance in youth remains debatable.

Several studies assessed balance in children by using the dual-task model. The results of these studies showed that concurrent performance of cognitive and motor tasks affect motor skills of children in the 7-9-year-old age groups [22,27,37]. Other studies also showed that 4-6-year-old children had conflicts in combining visual and sensory information to control posture but 7-10-year-old children had no difficulty in processing visual and sensory information for balance control [11,38]. Olivier et al. also showed that attentional constraints have a crucial role in cognitive-motor interference [10]. The results of the former study showed that a shift occurred in eight-year-old children and they could prioritize their attentional resources, even though they have not reached maturity at the age of eleven.

Although previous studies found a relationship between postural control in the bipedal standing position, age, and involvement in a cognitive task, Ruffieux et al. (2015) suggested that there is only feeble evidence for a trend towards enlarged DT costs in children [39]. Given the confounding results and the necessity for further studies in this field using a larger sample size, the study aimed to assess the effect of dual tasks on balance during manipulation of visual information, the base of support, and cognitive dual tasks in 7-12-year-old children and adults. The results could be used in many training fields, including physical education and sports for young adults. Therefore, the aim of this study was to answer these questions: Does the balance of children become similar to adults by the age of 12 ? Which sensory system has the greatest impact on the balance of children and adults? It was assumed that balance control improves with advancing age and postural sway (PS) increases when manipulating task demands at all ages in both genders. 


\section{Materials and Methods}

\subsection{Participants}

This research is of a descriptive-comparative type. Children from 7 to 12 years of age participated in this study (210 girls and 210 boys). Participants were 420 children, grouped into 6 ages (each group with 35 girls and 35 boys), and 20 adults (10 men and 10 women; age $=23.8 \pm 2.4$ years). All participants were sedentary. The children were selected from the schools of Hamedan city by the cluster random sampling method and were recruited at local elementary schools of different social levels. Young adults were also selected from the Azad University of Hamedan by using convenience sampling. The exclusion criteria were neurological, musculoskeletal, or sensory-motor disorder and a high body mass index, which could affect balance and cognitive function. Consent forms were collected from all the participants. The research protocol was approved by the ethics committee of Azad University of Hamedan (Code No.: 12 June 2019, with 5887/10/35/16/13).

\subsection{Protocol}

This protocol was performed in the biomechanics laboratory of Islamic Azad University, Hamadan Branch. PS was measured using COP displacement at ML and AP directions for $20 \mathrm{~s}$ in three trials in each condition. COP was calculated as mentioned by Karlsson et al. [2]. There were 8 conditions (combination of 2 bases of support, 2 visual conditions, and 2 cognitive conditions), and therefore a total of 24 trials. There was a 1-min rest between each test and the order of trials was selected randomly [22]. To assess the static balance, participants were asked to stand on a force plate and their postural sway were recorded in the following eight conditions included: (a) standing with feet together and open eyes while performing dual tasks (TOD); (b) standing with feet together and open eyes without performing dual tasks (TOS); (c) standing with feet together and closed eyes while performing dual tasks (TCD); (d) standing with feet together and closed eyes without performing dual tasks (TCS); (e) standing on a single limb with open eyes while performing dual tasks (SOD); (f) standing on a single limb with open eyes without performing dual tasks (SOS); (g) standing on a single limb with closed eyes while performing dual tasks (SCD); (h) standing on a single limb with closed eyes without performing dual tasks (SCS). Tasks (a) and (b) were the basic tasks.

Manipulation of the base of support was standing on either two legs or one leg. In the position of standing with feet together, the participant stood barefoot while keeping hands on the hips and placing both legs on the center of the force plate and keeping the feet were close to each other. In the position of standing on a single limb, the participants were asked to put one leg on the center of force place and bend the other knee to 90 degrees and put their hands on the waist and do not allow the legs to touch each other. Visual manipulation was open and closed eyes. In the open eyes condition, the participants looked at the image of a dot placed on the wall at a two meters distance. In the closed eyes condition, a blindfold was used. The Digit Span Forward (the Wechsler working memory subtest) was used to assess dual tasks [28]. The software was manufactured by Sina Institute of Psychology, Tehran, Iran. In this subtest, the figures are read then the participant should recite them in the sequence they were presented. The number of correct answers would be calculated within twenty seconds with and without concurrent motor task

\subsection{Data Processing}

Postural sway (PS) was measured using COP displacement with using the Kistler Force plate (Type 9286, Kistler Instrument AG, Winterthur, Switzerland) at a frequency of $1000 \mathrm{~Hz}$. The data were filtered using a fourth-order low-pass Butterworth filter with a $20 \mathrm{~Hz}$ cut-off frequency. These data were collected and stored by using Bioware software (Version 3.21, Kistler Instrument Corp., Kistler AG, Winterthur, Switzerland). The variables of postural sway in the ML and AP directions for $20 \mathrm{~s}$ were obtained directly from the Bioware software. 


\subsection{Statistical Analysis}

This study had two intergroup factors (age and gender) and four intragroup factors, namely, base of support (feet together/single limb), vision (open eyes/closed eyes), task (dual task/single task), and direction (AP/ML). A two-way ANOVA with repeated measures test was used for the statistical analysis. When a significant $F$ value was achieved, a Bonferroni post hoc test was used to detect differences in the measures. Cohen's d [30] was also used to calculate the effects of training (effect size (ES)). Statistical analysis was performed using Statistical Package for Social Sciences (SPSS, IBM Corp., Armonk, NY, USA) version 21 and the statistical significance was $p<0.05$.

\section{Results}

Table 1 shows the height, weight, and BMI of the participants.

Table 1. Demographic characteristics of the participants.

\begin{tabular}{|c|c|c|c|c|c|c|c|}
\hline \multirow{2}{*}{ Age (year) } & \multirow{2}{*}{$n$} & \multicolumn{2}{|c|}{ Height (m) } & \multicolumn{2}{|c|}{ Body Mass (kg) } & \multicolumn{2}{|c|}{ BMI $\left(\mathrm{kg} / \mathrm{m}^{2}\right)$} \\
\hline & & Women & Men & Women & Men & Women & Men \\
\hline 7 & 70 & $1.23(0.05)$ & $1.22(0.05)$ & $23.75(3.57)$ & $22.85(2.70)$ & $15.47(1.78)$ & $15.26(1.08)$ \\
\hline 8 & 70 & $1.27(0.06)$ & $1.29(0.06)$ & $24.79(4.81)$ & $26.64(4.44)$ & $15.13(2.28)$ & $15.78(1.82)$ \\
\hline 9 & 70 & $1.33(0.07)$ & $1.34(0.06)$ & $30.39(6.86)$ & $29.44(6.10)$ & $16.79(2.51)$ & $16.25(2.43)$ \\
\hline 10 & 70 & $1.41(0.04)$ & $1.40(0.06)$ & $32.49(5.80)$ & $33.42(7.03)$ & $16.24(2.50)$ & $16.98(2.91)$ \\
\hline 11 & 70 & $1.46(0.04)$ & $1.47(0.06)$ & 37.77 (5.19) & $38.32(7.46)$ & $17.59(2.42)$ & $17.60(2.55)$ \\
\hline 12 & 70 & $1.52(0.06)$ & $1.48(0.05)$ & 41.59 (9.55) & $39.12(5.98)$ & $17.85(3.33)$ & $17.77(2.01)$ \\
\hline Adult & 20 & $1.62(0.06)$ & $1.82(0.07)$ & $52.32(6.73)$ & $84.26(10.3)$ & $19.94(2.74)$ & $24.67(2.70)$ \\
\hline
\end{tabular}

\subsection{Age and Gender}

Multivariate analysis of variance showed that age $(\mathrm{F}(6,426)=3.85$, sig $=0.001$, Eta $=0.05)$ and gender $(F(1,426)=2.85, \operatorname{sig}=0.000, \mathrm{Eta}=0.07)$ had a significant effect on PS. There was no significant age difference in the basic homework. The results showed that there was no significant age difference in the basic tasks. The greatest PS belonged to 8-year-old children and the lowest to adults. Significant differences were found in PS between both genders in both the AP and ML directions in the TOD, TCD, SOD, SOS, SCD, and SCS tasks $(p<0.05)$ (Tables 2 and 3).

Table 2. Comparison of male and female participants regarding PS in the AP direction.

\begin{tabular}{ccccccccc}
\hline Task & & 7 Years & 8 Years & 9 Years & 10 Years & 11 Years & 12 Years & Adult \\
\hline TOD & Men & $0.79(0.34)$ & $0.78(0.23)$ & $0.68(0.30)$ & $0.80(0.54)$ & $0.68(0.39)$ & $0.69(0.27)$ & $0.80(0.24)$ \\
Sig. & Women & $0.89(0.51)$ & $0.91(0.60)$ & $1.05(0.62)$ & $1.15(0.79)$ & $0.99(0.64)$ & $0.92(0.60)$ & $0.92(0.67)$ \\
T & & 0.29 & 0.24 & 0.00 & 0.03 & 0.01 & 0.04 & 0.60 \\
TOS & Men & $0.88(0.32)$ & $0.90(0.29)$ & $0.77(0.24)$ & $0.84(0.34)$ & $0.79(0.37)$ & $0.79(0.28)$ & $0.65(0.33)$ \\
Sig. & Women & $0.77(0.22)$ & $0.83(0.35)$ & $0.90(0.40)$ & $0.81(0.31)$ & $0.83(0.74)$ & $0.79(0.33)$ & $0.54(0.16)$ \\
T & & 0.10 & 0.37 & 0.11 & 0.68 & 0.77 & 0.99 & 0.38 \\
TCD & Men & $0.85(0.20)$ & $0.90(0.34)$ & $0.80(0.24)$ & $0.79(0.27)$ & $0.84(0.49)$ & $0.80(0.34)$ & $0.90(0.38)$ \\
Sig. & Women & $0.87(0.40)$ & $0.88(0.49)$ & $1.01(0.46)$ & $1.07(0.64)$ & $0.97(0.56)$ & $0.94(0.35)$ & $0.68(0.24)$ \\
T & & 0.84 & 0.87 & 0.01 & 0.20 & 0.32 & 0.10 & 0.04 \\
TCS & Men & 0.19 & 0.16 & 2.39 & 2.41 & 1.01 & 1.65 & 2.34 \\
Sig. & Women & $0.83(0.25$ & $0.84(0.37)$ & $0.81(0.22)$ & $0.85(0.36)$ & $0.69(0.22)$ & $0.85(0.28)$ & $0.65(0.15)$ \\
T & & 0.13 & 0.23 & 0.56 & 0.73 & 0.09 & 0.61 & 0.78 \\
& & 1.54 & 1.22 & 0.58 & 0.35 & 1.73 & 0.51 & 0.29 \\
\hline
\end{tabular}


Table 2. Cont.

\begin{tabular}{ccccccccc}
\hline Task & & 7 Years & 8 Years & 9 Years & 10 Years & 11 Years & 12 Years & Adult \\
\hline \multirow{2}{*}{ SOD } & Men & $1.18(0.42)$ & $1.08(0.42)$ & $0.90(0.26)$ & $0.85(0.22)$ & $1.02(0.65)$ & $0.98(0.35)$ & $0.78(0.28)$ \\
Sig. & Women & $0.92(0.38)$ & $0.81(0.29)$ & $0.87(0.23)$ & $0.86(0.36)$ & $0.87(0.28)$ & $0.84(0.20)$ & $0.68(0.09)$ \\
T & & 0.00 & 0.00 & 0.60 & 0.96 & 0.21 & 0.03 & 0.33 \\
& & 2.76 & 3.09 & 0.52 & 0.05 & 1.25 & 2.17 & 1.03 \\
SOS & Men & $1.32(0.47)$ & $1.41(0.50)$ & $1.08(0.53)$ & $1.09(0.34)$ & $1.19(0.84)$ & $1.09(0.40)$ & $0.73(0.25)$ \\
Sig. & & $0.06(0.44)$ & $0.94(0.32)$ & $1.02(0.35)$ & $1.07(0.38)$ & $0.93(0.32)$ & $1.04(0.34)$ & $0.78(0.21)$ \\
T & & 0.02 & 0.00 & 0.58 & 0.80 & 0.09 & 0.59 & 0.62 \\
SCD & Men & $1.98(0.61)$ & $2.41(0.89)$ & $2.07(1.07)$ & $2.10(0.59)$ & $1.96(0.79)$ & $2.01(071)$ & $1.67(1.07)$ \\
Sig. & Women & $1.62(0.64)$ & $1.47(0.53)$ & $1.82(0.83)$ & $1.91(0.00)$ & $1.72(0.60)$ & $1.77(0.59)$ & $1.38(0.65)$ \\
T & & 0.02 & 0.00 & 0.28 & 0.37 & 0.15 & 0.14 & 0.48 \\
SCS & Men & 2.38 & 5.39 & 1.08 & 0.90 & 1.43 & 1.50 & 0.73 \\
Sig. & Women & $2.08(1.03)$ & $1.82(0.68)$ & $1.76(0.61)$ & $2.05(1.04)$ & $2.07(0.92)$ & $2.02(1.00)$ & $1.45(0.45)$ \\
T & & 0.38 & 0.00 & 0.01 & 0.03 & 0.65 & 0.04 & 0.52 \\
\hline
\end{tabular}

Abbreviations: TOD $=$ feet together and open eyes with dual tasks; TOS $=$ feet together and open eyes without dual tasks; TCD = feet together and closed eye with dual tasks; TCS $=$ feet together and closed eyes without performing dual tasks; SOD = single limb with open eyes with dual tasks; SOS = single limb with open eyes without dual tasks; SCD = a single limb with closed eyes with dual tasks; SCS = single limb with closed eyes without dual tasks.

Table 3. Comparison of male and female participants regarding PS in the ML direction.

\begin{tabular}{|c|c|c|c|c|c|c|c|c|}
\hline Task & & 7 Years & 8 Years & 9 Years & 10 Years & 11 Years & 12 Years & Adult \\
\hline \multirow{2}{*}{ TOD } & Men & $0.88(0.45)$ & $0.86(0.32)$ & $0.75(0.40)$ & $0.84(0.48)$ & $0.75(0.45)$ & $0.66(0.27)$ & $0.50(0.18)$ \\
\hline & Women & $0.73(0.31)$ & $0.70(0.23)$ & $0.63(0.20)$ & $0.71(0.41)$ & $0.60(0.22)$ & $0.76(0.61)$ & $0.66(0.71)$ \\
\hline Sig. & & 0.12 & 0.02 & 0.12 & 0.21 & 0.08 & 0.42 & 0.49 \\
\hline $\mathrm{T}$ & & 1.55 & 2.46 & 1.56 & 1.26 & 1.78 & 0.82 & 0.71 \\
\hline \multirow{2}{*}{ TOS } & Men & $0.98(0.33)$ & $0.91(0.37)$ & $0.85(0.39)$ & $1.04(0.58)$ & $0.96(0.46)$ & $0.87(0.41)$ & $0.68(0.58)$ \\
\hline & Women & $0.79(0.24)$ & $0.88(0.38)$ & $0.83(0.31)$ & $0.71(0.30)$ & $0.83(0.89)$ & $0.78(0.32)$ & $0.63(0.44)$ \\
\hline Sig. & & 0.01 & 0.71 & 0.81 & 0.00 & 0.46 & 0.34 & 0.85 \\
\hline $\mathrm{T}$ & & 2.76 & 0.375 & 0.24 & 2.99 & 0.74 & 0.98 & 0.19 \\
\hline \multirow{2}{*}{ TCD } & Men & $0.93(0.26)$ & $1.03(0.35)$ & $0.80(0.26)$ & $0.83(0.33)$ & $0.86(0.43)$ & $0.85(0.33)$ & 1.48 (1.65) \\
\hline & Women & $0.86(0.39)$ & $0.78(0.14)$ & $0.78(0.22)$ & $0.76(0.20)$ & $0.75(0.17)$ & $0.78(0.21)$ & $0.62(0.42)$ \\
\hline Sig. & & 0.34 & 0.00 & 0.78 & 0.27 & 0.18 & 0.29 & 0.13 \\
\hline $\mathrm{T}$ & & 0.96 & 3.95 & 0.28 & 1.11 & 1.35 & 1.07 & 0.16 \\
\hline \multirow{2}{*}{ TCS } & Men & $1.05(0.29)$ & $1.07(0.40)$ & $0.87(0.34)$ & $0.95(0.38)$ & $0.83(0.30)$ & $0.85(1.00)$ & $0.34(0.09)$ \\
\hline & Women & $0.90(0.35)$ & $0.93(0.27)$ & $0.83(0.27)$ & $0.81(0.26)$ & $0.80(0.22)$ & $0.79(0.22)$ & $0.79(0.16)$ \\
\hline Sig. & & 0.04 & 0.09 & 0.53 & 0.06 & 0.61 & 0.13 & 0.00 \\
\hline $\mathrm{T}$ & & 2.02 & 1.71 & 0.64 & 1.90 & 0.51 & 1.52 & 7.45 \\
\hline \multirow[b]{2}{*}{ SOD } & Men & $0.97(0.52)$ & $0.85(0.43)$ & $0.76(0.37)$ & $0.67(0.18)$ & $0.75(0.35)$ & $0.76(0.48)$ & $0.60(0.08)$ \\
\hline & Women & $0.61(0.21)$ & $0.66(0.37)$ & $0.58(0.16)$ & $0.56(0.16)$ & $0.64(0.25)$ & $0.57(0.15)$ & $0.55(0.13)$ \\
\hline \multirow{2}{*}{$\begin{array}{l}\text { Sig. } \\
\text { T }\end{array}$} & & 0.00 & 0.06 & 0.01 & 0.01 & 0.13 & 0.30 & 0.37 \\
\hline & & 3.84 & 1.93 & 2.56 & 2.54 & 1.53 & 2.25 & 0.91 \\
\hline \multirow{2}{*}{ SOS } & Men & $1.20(0.71)$ & $1.13(0.53)$ & $0.85(0.42)$ & $0.92(0.37)$ & $0.77(0.29)$ & $0.79(0.38)$ & $0.57(0.21)$ \\
\hline & Women & $0.81(0.41)$ & $0.75(0.31)$ & $0.75(0.41)$ & $0.72(0.41)$ & $0.70(0.26)$ & $0.73(0.48)$ & $0.55(0.12)$ \\
\hline \multirow{2}{*}{$\begin{array}{l}\text { Sig. } \\
\text { T }\end{array}$} & & 0.01 & 0.00 & 0.33 & 0.03 & 0.25 & 0.46 & 0.79 \\
\hline & & 2.80 & 3.65 & 0.983 & 2.13 & 1.15 & 0.74 & 0.26 \\
\hline \multirow{2}{*}{ SCD } & Men & $1.21(0.99)$ & $2.37(1.10)$ & $1.94(1.12)$ & $2.05(0.93)$ & $1.75(0.91)$ & $1.80(1.44)$ & $1.63(0.92)$ \\
\hline & Women & $1.45(0.65)$ & $1.49(0.59)$ & $1.66(1.02)$ & $1.81(1.67)$ & $1.66(0.95)$ & $1.58(0.77)$ & $1.29(0.62)$ \\
\hline Sig. & & 0.00 & 0.00 & 0.28 & 0.29 & 0.66 & 0.03 & 0.35 \\
\hline $\mathrm{T}$ & & 3.79 & 4.18 & 1.09 & 1.07 & 0.44 & 2.20 & 0.95 \\
\hline
\end{tabular}


Table 3. Cont.

\begin{tabular}{ccccccccc}
\hline Task & & 7 Years & 8 Years & 9 Years & 10 Years & 11 Years & 12 Years & Adult \\
\hline \multirow{2}{*}{ SCS } & Men & $2.45(0.96)$ & $2.93(1.71)$ & $2.16(1.44)$ & $2.61(1.68)$ & $1.81(0.95)$ & $1.85(3.06)$ & $1.12(0.74)$ \\
Sig. & Women & $1.80(0.97)$ & $1.69(0.60)$ & $1.55(0.81)$ & $2.18(1.84)$ & $1.93(1.25)$ & $1.72(1.07)$ & $1.32(0.42)$ \\
T & & 0.01 & 0.00 & 0.03 & 0.32 & 0.66 & 0.00 & 0.46 \\
\hline
\end{tabular}

Abbreviations: TOD $=$ feet together and open eyes with dual tasks; TOS $=$ feet together and open eyes without dual tasks; TCD = feet together and closed eye with dual tasks; TCS $=$ feet together and closed eyes without performing dual tasks; SOD = single limb with open eyes with dual tasks; SOS = single limb with open eyes without dual tasks; SCD = a single limb with closed eyes with dual tasks; SCS = single limb with closed eyes without dual tasks.

\subsection{Visual Manipulation}

The results showed that the main effect of visual factor has a significant effect on PS (F $(426)=574.3, \mathrm{sig}=0.000, \mathrm{Eta}=0.57)$, where in the closed eye condition the amount of sway was significantly greater than the open eye. The interaction between visual and age was significant $(\mathrm{F}(426)=2.23, \mathrm{sig}=0.039, \mathrm{Eta}=0.03)$. The visual factor also had a significant interaction with gender, as PS significantly increased in men compared to women while their eyes were closed $(\mathrm{F}(426)=17.77$, sig $=0.000$, Eta $=0.04)($ Figure 1A). The visual factor had no significant interaction with task $(\mathrm{F}(426)=0.181$, sig $=0.67, \mathrm{Eta}=0.000)$ (Tables 1 and 2).
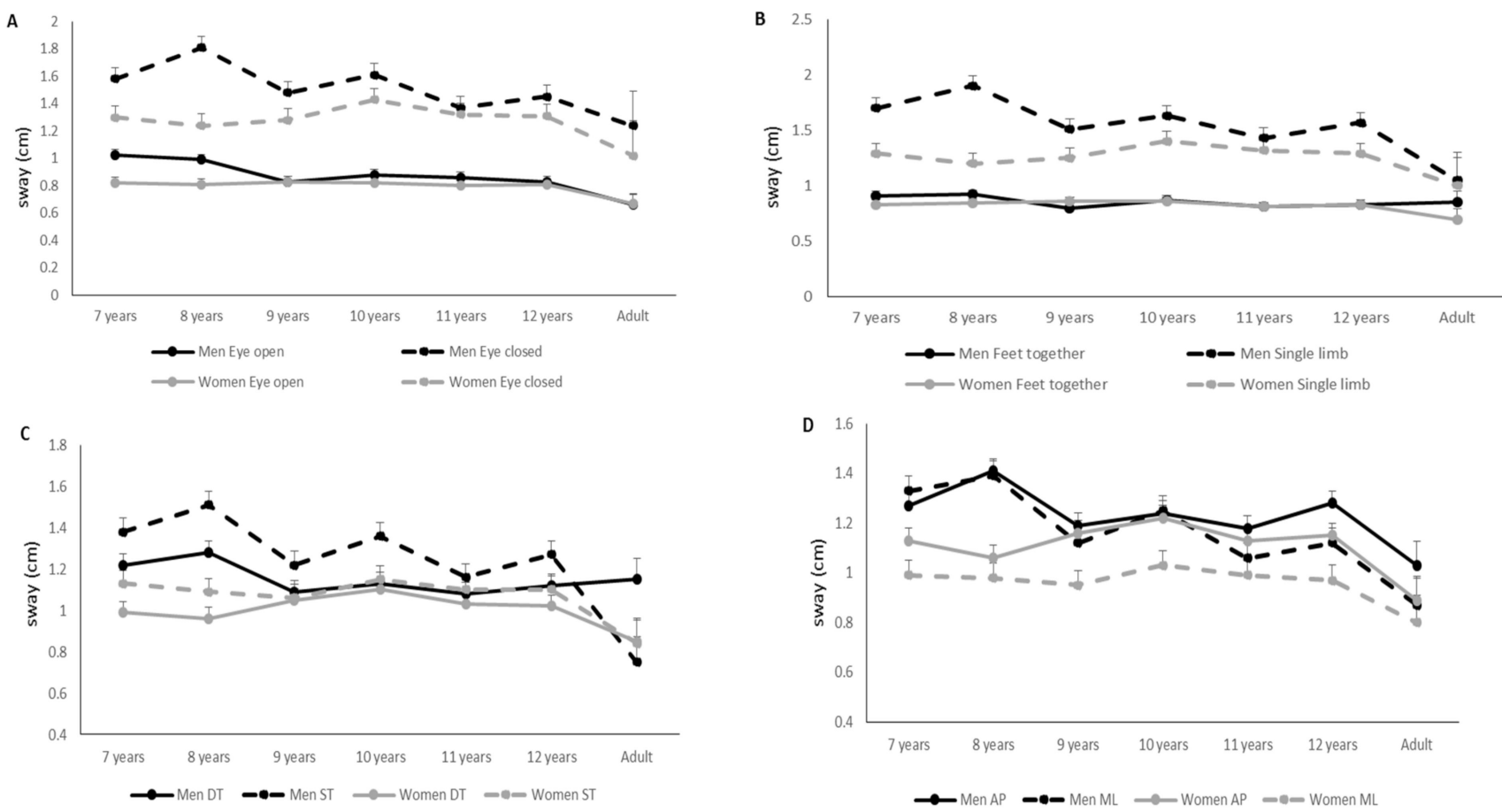

Figure 1. Cont. 

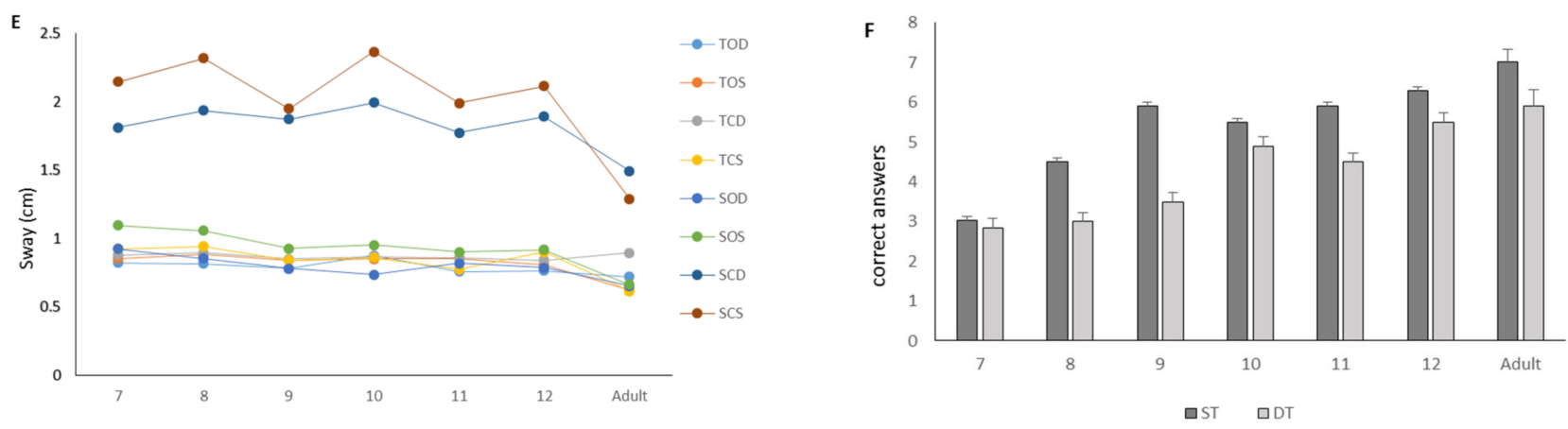

Figure 1. (A) Interaction of age and gender with the visual factor. (B) Interaction of age and gender with the factor of base of support. (C) Interaction of age and gender with the task factor. (D) Interaction of age and gender with the direction factor. (E) Comparison of PS at different ages while performing different tasks. (F) Comparison of cognitive function between ST and DT.

\subsection{Manipulation of the Base of Support}

PS was significantly greater in the single limb compared to feet together $(\mathrm{F}(426)=412.4$, sig $=0.000, \mathrm{Eta}=0.49)$. Interaction of age and the base of support was significant $(\mathrm{F}(426)=2.19, \operatorname{sig}=0.043, \mathrm{Eta}=0.03)$. Gender had also a significant interaction with the base of support. Results showed that PS was greater in men than in women in the single limb test $(\mathrm{F}(426)=24.03, \mathrm{sig}=0.000, \mathrm{Eta}=0.05)($ Figure $1 \mathrm{~B})$. Pairwise comparisons between tasks showed that manipulation of the base of support increased with age difference in PS in TOD and SOD tasks $(p>0.05)$. There was a significant difference in PS between 7- and 8-year-old children and adults in the ML direction and between 7- and 12-year-old children and adults in the AP direction $(p>0.05)$.

\subsection{Cognitive Load Manipulation}

The results showed that the main effect of task factor had a significant effect on PS. PS was significantly greater in DT compared to ST $(\mathrm{F}(426)=22.15$, sig $=0.000$, Eta $=0.05)$. However, cognitive DT had no significant interaction with gender $(\mathrm{F}(426)=1.85$, sig $=0.18$, Eta $=0.004)$ (Figure 1C).

Overall, according to this result, PS during the dual task decreased in both genders compared to the single task. Age also had a significant interaction with base of support. Therefore, cognitive DT had significant effects on PS at different age groups (F (426) $=4.24$, sig $=0.000$, Eta $=0.056$ ). PS decreased in 7- and 12-year-old participants while performing DT at all tasks. However, PS increased in adults while performing DT at all tasks.

\subsection{AP and ML Directions}

The main effect of direction was significant, as PS was significantly greater at AP than that ML $(\mathrm{F}(426)=56.5, \mathrm{sig}=0.000, \mathrm{Eta}=0.12)$. Direction and gender also had a significant interaction $(\mathrm{F}(426)=21.29$, sig $=0.000$, Eta $=0.05)$, as PS was significantly smaller at ML in women than men but in the AP direction PS was similar in men and women (Figure 1D,E).

\subsection{Cognitive Task}

According to Figure $1 \mathrm{~F}$, the single cognitive tasks in seven- and eight-year-old children were significantly lower than in adults $(p<0.05)$. The correct answers in DT were lower than ST at all ages, especially as the complexity of motor tasks increased. There was also a significant difference between 7-year-old and 8-year-old children in ST and DT $(p>0.05)$. The correct answers were also greater in girls than boys $(p<0.05)$.

\section{Discussion}

The results showed that PS decreased with increasing age and increased while manipulating task demands and visual information. The results showed that manipulation of 
visual information increased PS in all age groups. PS did not change when eyes were open between different age groups, but PS was greater in both men and women when eyes were closed, especially in children under 9 years of age. Therefore, children are more dependent on visual information to maintain postural stability although their visual structure might be mature. The results of previous studies also showed the importance of visual information in children under 12 years of age compared to adults [8,40-42]. These results were consistent with the results of the study by Gouleme et al. (2014), who showed that balance control became more challenging as task demands increased. COP velocity and range of motion increased as the base of support was less stable and eyes were closed [43].

PS increased at all age groups while manipulating the base of support. There was no difference in PS between men and women at all age groups in standing with feet together. However, PS increased while standing on a single limb between the 7-year-old and 12-yearold participants, but adults experienced less changes in PS. Comparison of PS in different tasks showed that PS was different in adults and children under the age of twelve while manipulating visual information and the base of support. However, children above twelve years of age could control their posture as stable as adults. According to the previous studies, 7-year-old children are not experienced enough for the development of postural control and motor skills although the structures responsible for motor control are mature at this age $[34,41,44,45]$. Therefore, PS would also be greater in 7-year-old children as task complexity increased. Shams et al. also showed that 14-16-year-old adolescents could control their postures as stable as adults [46]. Their findings also showed that women could better control their balance than men. These results are consistent with our results and previous studies [1,46].

Single cognitive tasks could be better executed with increasing age and women acquired higher scores in cognitive tasks than men. These results are consistent with the results of the study by Villarrasa et al. (2019), who showed that cognitive tasks were dependent on age. Higher scores would be gained in cognitive tasks as age increases [24]. Previous studies also showed that women were more successful in verbal and memory tasks while men accomplished more computational tasks than women $[23,47,48]$. Therefore, women acquired higher scores in the cognitive tasks in this study since the task was related to memory.

PS was smaller in DT than ST in 7-12-year-old participants. However, PS significantly increased in young male adults in DT compared to ST. Nevertheless, PS in women was lower than men in both ST and DT. These results are consistent with the results of the study by Schaefer et al., who reported that 9-year-old children were able to recite and visualize words exactly as adults [26]. They showed that little children prioritized motor tasks to control their balance, especially in the case of difficult motor tasks. Therefore, they failed to perform concurrent cognitive tasks. Children prioritize motor tasks to avoid falling. This is because they cannot divide their attentional resources between motor and cognitive tasks $[23,26]$. Blanchard et al. showed that PS was smaller in children compared to adults in case of higher cognitive demands [22]. They showed that children adopt different strategies to perform concurrent dual tasks compared to adults. However, Olivier et al. showed that concurrent cognitive tasks (strops) reduced motor function in children [27]. Olivier et al. also showed that attention to motor tasks led to the recruitment of more motor units (especially the lower extremity) that reduced postural stability [49]. Recruitment of more motor units caused variability in motor output as noise increased postural sway. According to the results of previous studies, postural sway increases in young adults because they focus on motor tasks that consciously control posture whereas children focus on cognitive tasks that automatically control posture.

The results of this study showed that PS could not reach the threshold of adults in the children up to the age of twelve in case of higher task demands in both the AP and ML directions. De Sá et al. showed that PS increased in case of higher task demands and PS decreased in advancing age in both directions [41]. In contrast to this study, some studies showed that 10-year-old adolescents could control their static balance as stable 
as adults $[35,50]$. Similar to this study, other studies showed that postural control would be mature at the age of 14; therefore, the central and peripheral structures responsible for postural control are still developing during adolescence [8,46,51]. In addition to the development of sensory systems (visual, somatosensory, vestibular, and neuromuscular system), other factors such as experience, motivation, concentration, and fatigue also affect posture control and improve balance control in adulthood. A limitation of this study has been the inability to assess the balance of individuals at a certain time of day.

\section{Conclusions}

This study offered important information about age-related changes in balance control in childhood and adolescence. The findings showed that postural control improved with advancing age in all tasks. PS in 9-year-old children was as small as adults in basic tasks. However, a significant difference was found in PS between children and adults in case of higher task demands. Therefore, postural stability has not matured up to the age of 12 . The base of support had a greater impact on PS than visual information. However, concurrent cognitive tasks showed that children should adopt different strategies to control posture compared to adults.

Author Contributions: Conceptualization, A.G., M.M., A.A.J. and E.A.; methodology, E.A.; software, M.M.; validation, M.M. and M.A.; formal analysis, A.A.J.; investigation, M.A.; data curation, A.G.; writing-original draft preparation, E.A.; writing-review and editing, M.A.; visualization, A.G.; supervision, E.A.; project administration, M.A.; funding acquisition, M.A. All authors have read and agreed to the published version of the manuscript.

Funding: This research received no external funding.

Institutional Review Board Statement: The study was conducted according to the guidelines of the Declaration of Helsinki, and approved by the Institutional Review Board of the Islamic Azad University of Hamedan (12 June 2019, with code number: 5887/10/35/16/13).

Informed Consent Statement: Informed consent was obtained from all subjects involved in the study.

Data Availability Statement: Data will be made available upon contacting the corresponding author.

Acknowledgments: The authors gratefully acknowledge the contributions of the subjects who participated in the study.

Conflicts of Interest: The authors declare no conflict of interest.

\section{References}

1. Mickle, K.J.; Munro, B.J.; Steele, J.R. Gender and age affect balance performance in primary school-aged children. J. Sci. Med. Sport 2011, 14, 243-248. [CrossRef] [PubMed]

2. Karlsson, A.; Frykberg, G. Correlations between force plate measures for assessment of balance. Clin. Biomech. 2000, 15, 365-369. [CrossRef]

3. Alexandrov, P.; Percy, M.; Lukiw, W.J. Chromosome 21-Encoded microRNAs (mRNAs): Impact on Down's syndrome and trisomy-21 linked disease. Cell Mol. Neurobiol. 2018, 38, 769-774. [CrossRef] [PubMed]

4. Raymakers, J.; Samson, M.; Verhaar, H. The assessment of body sway and the choice of the stability parameter (s). Gait Posture 2005, 21, 48-58. [CrossRef]

5. Era, P.; Sainio, P.; Koskinen, S.; Haavisto, P.; Vaara, M.; Aromaa, A. Postural balance in a random sample of 7979 subjects aged 30 years and over. Gerontology 2006, 52, 204-213. [CrossRef]

6. Albertsen, I.M.; Ghédira, M.; Gracies, J.-M.; Hutin, É. Postural stability in young healthy subjects-Impact of reduced base of support, visual deprivation, dual tasking. J. Electromyogr. Kinesiol. 2017, 33, 27-33. [CrossRef]

7. Breniére, Y.; Bril, B. Development of postural control of gravity forces in children during the first 5 years of walking. Exp. Brain Res. 1998, 121, 255-262. [CrossRef]

8. Rival, C.; Ceyte, H.; Olivier, I. Developmental changes of static standing balance in children. Neurosci. Lett. 2005, 376, 133-136. [CrossRef]

9. Kirshenbaum, N.; Riach, C.; Starkes, J. Non-linear development of postural control and strategy use in young children: A longitudinal study. Exp. Brain Res. 2001, 140, 420-431. [CrossRef]

10. Olivier, I.; Cuisinier, R.; Vaugoyeau, M.; Nougier, V.; Assaiante, C. Age-related differences in cognitive and postural dual-task performance. Gait Posture 2010, 32, 494-499. [CrossRef] 
11. Shumway-Cook, A.; Woollacott, M.; Kerns, K.A.; Baldwin, M. The effects of two types of cognitive tasks on postural stability in older adults with and without a history of falls. J. Gerontol. Ser. A Biol. Sci. Med. Sci. 1997, 52, M232-M240. [CrossRef]

12. Melzer, I.; Benjuya, N.; Kaplanski, J. Age-related changes of postural control: Effect of cognitive tasks. Gerontology 2001, 47, 189-194. [CrossRef]

13. Menant, J.C.; Schoene, D.; Sarofim, M.; Lord, S.R. Single and dual task tests of gait speed are equivalent in the prediction of falls in older people: A systematic review and meta-analysis. Ageing Res. Rev. 2014, 16, 83-104. [CrossRef]

14. Beauchet, O.; Berrut, G. Gait and dual-task: Definition, interest, and perspectives in the elderly. Psychol. Neuropsychiatr. Du Vieil. 2006, 4, 215-225.

15. Welford, A. Single-channel operation in the brain. Acta Psychol. 1967, 27, 5-22. [CrossRef]

16. Wickens, C.D. Multiple resources and performance prediction. Theor. Issues Ergon. Sci. 2002, 3, 159-177. [CrossRef]

17. Andersson, G.; Yardley, L.; Luxon, L. A dual-task study of interference between mental activity and control of balance. Am. J. Otol. 1998, 19, 632-637.

18. Pellecchia, G.L. Postural sway increases with attentional demands of concurrent cognitive task. Gait Posture 2003, 18, 29-34. [CrossRef]

19. Woollacott, M.; Shumway-Cook, A. Attention and the control of posture and gait: A review of an emerging area of research. Gait Posture 2002, 16, 1-14. [CrossRef]

20. Prado, J.M.; Stoffregen, T.A.; Duarte, M. Postural sway during dual tasks in young and elderly adults. Gerontology 2007, 53, 274-281. [CrossRef]

21. Huxhold, O.; Li, S.-C.; Schmiedek, F.; Lindenberger, U. Dual-tasking postural control: Aging and the effects of cognitive demand in conjunction with focus of attention. Brain Res. Bull. 2006, 69, 294-305. [CrossRef]

22. Blanchard, Y.; Carey, S.; Coffey, J.; Cohen, A.; Harris, T.; Michlik, S.; Pellecchia, G.L. The influence of concurrent cognitive tasks on postural sway in children. Pediatric Phys. Ther. 2005, 17, 189-193. [CrossRef]

23. Almajid, R.; Keshner, E. Role of gender in dual-tasking timed up and go tests: A cross-sectional study. J. Mot. Behav. 2019, 51, 681-689. [CrossRef]

24. Villarrasa-Sapiña, I.; Estevan, I.; Gonzalez, L.-M.; Marco-Ahulló, A.; García-Massó, X. Dual task cost in balance control and stability in children from 4-7 years old. Early Child Dev. Care 2019, 190, 2533-2542. [CrossRef]

25. Bustillo-Casero, P.; Villarrasa-Sapiña, I.; García-Massó, X. Effects of dual task difficulty in motor and cognitive performance: Differences between adults and adolescents. Hum. Mov. Sci. 2017, 55, 8-17. [CrossRef]

26. Schaefer, S.; Krampe, R.T.; Lindenberger, U.; Baltes, P.B. Age differences between children and young adults in the dynamics of dual-task prioritization: Body (balance) versus mind (memory). Dev. Psychol. 2008, 44, 747. [CrossRef]

27. Olivier, I.; Cuisinier, R.; Vaugoyeau, M.; Nougier, V.; Assaiante, C. Dual-task study of cognitive and postural interference in 7-year-olds and adults. Neuroreport 2007, 18, 817-821. [CrossRef]

28. Tsai, C.L.; Pan, C.Y.; Cherng, R.J.; Wu, S.K. Dual-task study of cognitive and postural interference: A preliminary investigation of the automatization deficit hypothesis of developmental co-ordination disorder. Child Care Health Dev. 2009, 35, 551-560. [CrossRef]

29. Nolan, L.; Grigorenko, A.; Thorstensson, A. Balance control: Sex and age differences in 9-to 16-year-olds. Dev. Med. Child Neurol. 2005, 47, 449-454. [CrossRef]

30. Woollacott, M.H.; Shumway-Cook, A. Changes in posture control across the life span-A systems approach. Phys. Ther. 1990, 70, 799-807. [CrossRef]

31. Hirabayashi, S.-i.; Iwasaki, Y. Developmental perspective of sensory organization on postural control. Brain Dev. 1995, 17, 111-113. [CrossRef]

32. Assaiante, C.; Amblard, B. An ontogenetic model for the sensorimotor organization of balance control in humans. Hum. Mov. Sci. 1995, 14, 13-43. [CrossRef]

33. Koolschijn, P.C.M.; Crone, E.A. Sex differences and structural brain maturation from childhood to early adulthood. Dev. Cogn Neurosci. 2013, 5, 106-118. [CrossRef] [PubMed]

34. Shumway-Cook, A.; Woollacott, M.H. The growth of stability: Postural control from a developmental perspective. J. Mot. Behav. 1985, 17, 131-147. [CrossRef]

35. Hatzitaki, V.; Zlsi, V.; Kollias, I.; Kioumourtzoglou, E. Perceptual-motor contributions to static and dynamic balance control in children. J. Mot. Behav. 2002, 34, 161-170. [CrossRef]

36. Steindl, R.; Kunz, K.; Schrott-Fischer, A.; Scholtz, A. Effect of age and sex on maturation of sensory systems and balance control. Dev. Med. Child Neurol. 2006, 48, 477-482. [CrossRef]

37. Schmid, M.; Conforto, S.; Lopez, L.; D’Alessio, T. Cognitive load affects postural control in children. Exp. Brain Res. 2007, 179, 375-385. [CrossRef]

38. Cuisinier, R.; Olivier, I.; Vaugoyeau, M.; Nougier, V.; Assaiante, C. Developmental approach of postural control from 7 to 11 years old and adults when proprioceptive inputs were disturbed. In Proceedings of the 4th International Conference on Enactive Interfaces, Grenoble, France, 19-24 November 2007; p. 69.

39. Ruffieux, J.; Keller, M.; Lauber, B.; Taube, W. Changes in standing and walking performance under dual-task conditions across the lifespan. Sports Med. 2015, 45, 1739-1758. [CrossRef] 
40. Peterson, M.L.; Christou, E.; Rosengren, K.S. Children achieve adult-like sensory integration during stance at 12-years-old. Gait Posture 2006, 23, 455-463. [CrossRef]

41. De Sá, C.d.S.C.; Boffino, C.C.; Ramos, R.T.; Tanaka, C. Development of postural control and maturation of sensory systems in children of different ages a cross-sectional study. Braz. J. Phys. Ther. 2018, 22, 70-76.

42. Valente, M. Maturational effects of the vestibular system: A study of rotary chair, computerized dynamic posturography, and vestibular evoked myogenic potentials with children. J. Am. Acad. Audiol. 2007, 18, 461-481. [CrossRef]

43. Gouleme, N.; Ezane, M.D.; Wiener-Vacher, S.; Bucci, M.P. Spatial and temporal postural analysis: A developmental study in healthy children. Int. J. Dev. Neurosci. 2014, 38, 169-177. [CrossRef]

44. Schmid, M.; Conforto, S.; Lopez, L.; Renzi, P.; D'Alessio, T. The development of postural strategies in children: A factorial design study. J. NeuroEngineering Rehabil. 2005, 2, 29. [CrossRef]

45. Sundermier, L.; Woollacott, M.; Roncesvalles, N.; Jensen, J. The development of balance control in children: Comparisons of EMG and kinetic variables and chronological and developmental groupings. Exp. Brain Res. 2001, 136, 340-350. [CrossRef]

46. Shams, A.; Vameghi, R.; Dehkordi, P.S.; Allafan, N.; Bayati, M. The development of postural control among children: Repeatability and normative data for computerized dynamic posturography system. Gait Posture 2020, 78, 40-47. [CrossRef]

47. Kimura, D. Sex, sexual orientation and sex hormones influence human cognitive function. Biomed. Rev. 1997, 7, 33-39. [CrossRef]

48. Van Hooren, S.; Valentijn, A.; Bosma, H.; Ponds, R.; Van Boxtel, M.; Jolles, J. Cognitive functioning in healthy older adults aged 64-81: A cohort study into the effects of age, sex, and education. Aging Neuropsychol. Cogn. 2007, 14, 40-54. [CrossRef]

49. Olivier, I.; Palluel, E.; Nougier, V. Effects of attentional focus on postural sway in children and adults. Exp. Brain Res. 2008, 185, 341-345. [CrossRef]

50. Figura, F.; Cama, G.; Capranica, L.; Guidetti, L.; Pulejo, C. Assessment of static balance in children. J. Sports Med. Phys. Fit. 1991, 31, 235-242.

51. Barozzi, S.; Socci, M.; Soi, D.; Di Berardino, F.; Fabio, G.; Forti, S.; Gasbarre, A.M.; Brambilla, D.; Cesarani, A. Reliability of postural control measures in children and young adolescents. Eur. Arch. Oto-Rhino-Laryngol. 2014, 271, 2069-2077. [CrossRef] 